\title{
Implementação e desenvolvimento da Prática como Componente Curricular em um Curso de Matemática
}

Implementation and development of practice as a curricular component in a Mathematics Course

\section{Resumo}

Regina Litz Lamblém ${ }^{1}$ Marco Aparecido Queiroz Duarte ${ }^{2}$ Irene Coelho Araujo ${ }^{3}$

A Prática como Componente Curricular (PCC), às vezes, é interpretada e trabalhada de forma diferente entre os cursos, ou até no mesmo curso. Por isso, ela ainda é assunto que carece de estudos e discussões. Este trabalho trata de como a PCC tem sido implementada, interpretada e trabalhada no Curso de Matemática da Unidade Universitária de Cassilândia da Universidade Estadual de Mato Grosso do Sul (UUC/UEMS) e fundamenta-se em Documentos Oficiais do Conselho Nacional de Educação, nos projetos pedagógicos que o curso teve ao longo de sua existência e nos relatos do Comitê Docente Estruturante (CDE), elaborados a partir das respostas dos professores do curso a um questionário sobre suas atuações em relação à PCC. Observa-se que as experiências vividas no Curso de Matemática da UUC/UEMS, a partir da inserção da PCC, foram significativas e abriram caminhos para que alguns docentes repensassem e reconstruíssem suas próprias práticas pedagógicas.

Palavras-chave: Prática docente. Educação Matemática. Formação de professores.

\section{Introdução}

A Prática como Componente Curricular (PCC) é um assunto que demanda muita discussão entre professores e alunos de cursos de formação de professores, pois várias são as formas de desenvolvê-la em um curso de licenciatura. Estabelecida pelas Resoluções CNE/CP № 1 de 18 de fevereiro de 2002 e CNE/CP № 2 de 19 de fevereiro de 2002 que tratam respectivamente das diretrizes curriculares nacionais para a formação de professores da educação básica e carga horária, a PCC deverá conter 400 horas e estar presente desde 0

\footnotetext{
${ }^{1}$ Doutora em Matemática, Professora efetiva do Curso de Matemática da Universidade Estadual de Mato Grosso do Sul - Unidade Universitária de Cassilândia, lamblem@uems.br.

${ }^{2}$ Doutor em Engenharia Elétrica, Professor efetivo do Curso de Matemática da Universidade Estadual de Mato Grosso do Sul - Unidade Universitária de Cassilândia, marco@uems.br.

${ }^{3}$ Doutora em Educação Matemática, Professora efetiva do Curso de Matemática da Universidade Estadual de Mato Grosso do Sul - Unidade Universitária de Cassilândia, irene@uems.br.
} 
início do curso, levar o aluno à observação e à reflexão de situações problemas, podendo ser enriquecida com tecnologias, narrativas orais e escritas de professores, produções de alunos, situações simuladoras e estudo de casos (BRASIL, 2002a; BRASIL, 2002b). A presença da PCC nos cursos de licenciatura e sua carga horária mínima de 400 horas volta a ser reforçada na resolução CNE/CP 02/2015 que altera a carga horária mínima dos cursos de licenciaturas para 3200 horas (BRASIL, 2015).

O presente relato fundamenta-se nos Documentos Oficiais que normatizam a PCC, nos Projetos Pedagógicos do Curso de Matemática da UUC/UEMS e é resultado de leituras, inquietações e discussões entre os professores desse Curso em torno da PCC. Busca-se uma relação teoria-prática na formação inicial do professor de Matemática e nos aspectos de planejamento e de organização curricular.

Para levantamento dos dados foi adotada a abordagem qualitativa de pesquisa e utilizada a análise bibliográfica e documental como meio na coleta das informações necessárias. Os procedimentos metodológicos utilizados foram feitos por meio da análise de documentos do próprio curso, de legislações que embasam a PCC e de registros de artigos que discorrem sobre $o$ assunto.

Nos últimos anos, a PCC tem sido amplamente discutida em cursos de licenciatura no Brasil. Várias são as publicações que tratam do assunto em cursos de diferentes áreas. Fernandes (2004) apresenta um relato de vários pensadores da área de educação a respeito da PCC, os quais deixam claro que a PCC proporciona a inserção dos acadêmicos no campo profissional desde o início do curso, articulando teoria e prática docente com o estágio supervisionado, a partir da metade do curso, dando identidade aos cursos de Licenciatura sem que eles sejam apêndices do bacharelado.

Brandalise e Trobia (2011) fazem um levantamento do processo de reformulação curricular do Curso de Matemática de uma universidade pública do estado do Paraná e analisam suas contribuições para a formação inicial, procurando implementar a PCC de acordo com a resolução CNE/CP N ${ }^{\circ} 1$ de 18 
de fevereiro de 2002. Os autores concluem que somente com a implementação total da PCC, a formação de novos professores será plena.

Calvo e Freitas (2011) investigam a compreensão de professores de um Curso de Letras sobre a PCC e como eles a realizam em sala de aula. Os resultados apontam um avanço no sentido de que os professores já reconheciam a importância e a necessidade de se contemplar o componente prático desde o início do curso e procuravam desenvolver atividades para que isso se efetuasse.

Nogueira e Pereira (2012a) analisam a concepção da PCC, a escolha das disciplinas em que a PCC está inserida e o planejamento para organização e aplicação da PCC no Curso de Matemática em uma instituição de ensino superior que obteve nota cinco (nota máxima) no Exame Nacional de Desempenho de Estudantes (ENADE) do ano de 2008. Tais análises possibilitaram verificar a importância da integração entre os professores no processo do planejamento e da construção do projeto pedagógico do curso visando à inserção da carga horária de PCC.

Hoerpes e Fernandes (2012) relatam a visão dos alunos do Curso de Matemática do Instituto Federal Catarinense (IFC). Para isso, alunos do quinto período, além do coordenador do curso, foram ouvidos. Os depoimentos mostram que alguns alunos compreendem e notam a realização da PCC no curso, enquanto que para outros ela ainda permanece confusa, assim como o estágio.

Nogueira e Pereira (2012b) analisam como a prática como componente curricular está distribuída na estrutura curricular do Projeto Pedagógico e como está sendo desenvolvida nas disciplinas do Curso de Licenciatura em Matemática da UNESP de Presidente Prudente, por meio de entrevistas com os professores do curso. Foi verificado que para cumprir o que exige a legislação sobre a PCC, além das disciplinas pedagógicas, as disciplinas de conteúdos específicos também foram contempladas com a PCC por meio de projetos articuladores, coordenados por um professor para cada série do curso. Na visão dos autores, a proposta de trabalhar via projetos articuladores estimula uma postura reflexiva, questionadora e de trabalho coletivo no ambiente escolar. 
Manrinque e Perentelli (2008) mostram estudos sobre a PCC em Cursos de Matemática de duas instituições de ensino superior da grande São Paulo, que são apresentados por meio de entrevistas com os coordenadores dos cursos e com os professores de prática de ensino. O estudo conclui que, embora as duas instituições se esforcem para fazer valer a PCC, ainda é necessário muito esforço e trabalho para que isso realmente aconteça.

Barbosa e Cassiani (2014) analisam num âmbito geral os documentos do Conselho Nacional de Educação com o objetivo de compreender os sentidos atribuídos à PCC e fazem uma análise dos sentidos da PCC nos documentos do Conselho Nacional de Educação. Os autores concluem que os textos oficiais ainda são um pouco confusos, permitindo várias interpretações.

Zabel e Malheiros (2016), assim como Barbosa e Cassiani (2014), analisam a legislação brasileira que norteia os cursos de licenciatura buscando um entendimento sobre a PCC. Neste trabalho, as autoras tentam dizer porque a PCC é proposta, como ela foi pensada e como tem sido implementada. Concluem que ainda é possível estabelecer um padrão de como as horas destinadas a PCC são/foram implementadas nos cursos. $E$ isso pode ser consequência da forma como foram estabelecidas essas novas resoluções, pois não houve total esclarecimento de como deveriam ser articuladas as horas de PCC nos cursos e, além disso, deu-se total autonomia aos cursos para defini-las em seus currículos. Pois, há cursos que distribuem as horas de PCC praticamente em todas as suas disciplinas, outros nas disciplinas de conteúdos específicos e pedagógicos e ainda outros que apresentam as horas de PCC integralmente em algumas disciplinas, geralmente voltadas para a prática de ensino.

Borin (2016) apresenta interpretações das resoluções CNE/CP 02/2002 e CNE/CP 02/2015 a respeito da PCC e mostra como professores do Curso de Matemática da Universidade Tecnológica Federal do Paraná (UTFPR) - Campus Curitiba, têm trabalhado nesse sentido. Nesse estudo, foi possível observar que até 2015, 36 atividades de PCC eram propostas no curso, sendo distribuídas em praticamente todas as disciplinas, com menos predominância nas disciplinas de 
formação pedagógica. Rocha (2015) analisa apenas a resolução CNE/CP 01/2002, por se tratar do primeiro documento oficial a citar a PCC, também buscando um entendimento sobre o assunto e como ele se diferencia do estágio curricular supervisionado.

Cerri e Dias (2016) provocam os licenciandos do Curso de Matemática do Instituto de Matemática e Estatística da Universidade de São Paulo (IME/USP), durante a disciplina de Análise Matemática, a fazerem reflexões sobre o ensino e aprendizagem dos tópicos trabalhados em tal disciplina. Propondo, durante um semestre, de dois a três trabalhos por grupo de alunos, que têm como principais objetivos destacar a articulação entre o conhecimento de conteúdo específico, adquirido no curso, e os conhecimentos profissionais, relacionados com a prática de sala de aula. Nesses trabalhos os alunos discutiam as dificuldades e as formas de abordagem dos assuntos, analisavam criticamente como tais temas eram tratados em livros e materiais didáticos. Tais trabalhos propiciaram aos alunos se apropriar melhor dos temas abordados na disciplina, já que percebiam sua relevância e o porquê destes estarem presentes em um curso de Licenciatura, isto é, sua relação com a Matemática ensinada na escola básica.

Com base nos relatos dos parágrafos anteriores fica claro que discussões sobre a PCC acontecem e ainda acontecerão por vários aspectos e são úteis para sua plena implementação nos cursos de formação de professores. Por isso, com o intuito de relatar como a PCC tem sido implementada e desenvolvida no Curso de Matemática da UUC/UEMS, socializamos neste trabalho as experiências que mais se destacaram no Curso.

Os dados utilizados foram coletados nos arquivos do curso na própria universidade ou produzidos pelos autores que são docentes no Curso de Matemática em questão. Os projetos pedagógicos do curso permitem compreender como se deu o processo de implantação da PCC ao longo dos anos, conforme descrito na próxima seção. 


\section{A carga horária de PCC no Curso de Matemática da UUC/UEMS}

O Curso de Matemática da UUC/UEMS foi criado no ano 2000 e teve três reformulações de projeto pedagógico, nos anos de 2005, 2011 e 2017. A primeira versão do Projeto Pedagógico do curso (UEMS, 2000) foi herdada de um Curso de Matemática de outra unidade universitária da UEMS, pois até 2010 havia um único projeto pedagógico para todos os cursos de Matemática da UEMS.

O Projeto Pedagógico de 2000 não versava sobre a PCC, pois era anterior à resolução CNE/CP № 1 de 18 de fevereiro de 2002. Nesse projeto pedagógico, a prática docente era desenvolvida apenas nas disciplinas de estágio, que faziam parte das duas últimas séries do curso. A reformulação do Projeto Pedagógico de 2000, que culminou no Projeto Pedagógico de 2005, ocorreu após a constatação da necessidade de uma melhor distribuição das disciplinas entre as séries do curso e, principalmente, pela necessidade do atendimento à resolução $\mathrm{CNE} / \mathrm{CP}$ № 1 de 18 de fevereiro de 2002, no que diz respeito à carga horária total do curso e a PCC (UEMS, 2005).

No Projeto Pedagógico de 2005, o curso era composto de 26 disciplinas, dessas, 14 tinham carga horária de prática, geralmente com 50\% da carga horária da disciplina, considerando as disciplinas de estágio. Porém, em algumas dessas disciplinas a PCC era considerada como a prática de conteúdos ministrados com vistas a aplicações da Matemática. Isso se deve ao fato dos textos oficiais serem um pouco confusos, conforme mencionado por Barbosa e Cassiani (2014).

A reformulação do Projeto Pedagógico de 2005, que culminou no Projeto Pedagógico de 2011, ocorreu buscando, novamente, uma melhor distribuição das disciplinas no curso, mas também foram suprimidas algumas disciplinas e inseridas outras que tornassem mais sólida a formação de professores.

A Prática como Componente Curricular (PCC) é composta por ações que podem ocorrer no interior das disciplinas curriculares e na inter-relação entre elas, configurando-se como momentos de observações e reflexões sobre 0 conteúdo curricular que está sendo estudado e a sua relação com a prática 
docente do futuro professor. (Projeto Pedagógico do Curso de Matemática, 2011, p. 18)

No Projeto Pedagógico de 2011, houve uma nova interpretação do que é PCC e, por isso, das 29 disciplinas do curso, 18 passaram a contemplá-la nos moldes da resolução CNE/CP № 1 de 18 de fevereiro de 2002. Ou seja, nesse projeto $62 \%$ das disciplinas tinham carga horária de PCC, enquanto que no anterior isto ocorria apenas em 54\% das disciplinas. Além disso, no Projeto Pedagógico de 2011, a carga horária total da PCC era de 482 horas aulas, distribuídas entre as disciplinas e variando de 5\% a 100\% da carga horária de cada disciplina, sem considerar as disciplinas de estágio supervisionado que estão inseridas nas duas últimas séries do curso. Porém, ainda havia uma confusão entre PCC e prática (aplicações de conteúdos de Matemática).

Entre 2016 e 2017, o projeto pedagógico foi novamente reformulado, com implementação no início de 2018. Dessa vez, buscando principalmente dar mais importância às disciplinas de prática de ensino e, consequentemente à PCC. Nesse novo projeto, a PCC está mais bem distribuída nas disciplinas, pois já há uma melhor interpretação sobre a mesma, ou seja, distinção entre PCC e prática. Nessa nova reformulação, o curso passou a ter 31 disciplinas sendo que destas, 13 têm PCC (42\%). Embora tenha havido diminuição no número de disciplinas com PCC, não houve redução de sua carga horária total. O que aconteceu foi uma melhor estruturação dela nas disciplinas.

\section{O desenvolvimento da PCC no Curso de Matemática da UUC/UEMS}

No início do ano de 2013, foi criado o Comitê Docente Estruturante (CDE) do Curso de Matemática da UUC/UEMS. Este comitê tem trabalhado com ações junto aos professores do curso visando a compreensão da PCC, dentre outros temas peculiares a implantação do Projeto Pedagógico.

Com o intuito de verificar como os professores estavam desenvolvendo a Prática como Componente Curricular, em 2015, o CDE elaborou e solicitou que os 
professores respondessem a um questionário com as seguintes perguntas: 1) A disciplina que você ministra tem prática como componente curricular? 2) Em caso de resposta afirmativa para a questão 1: a) qual é a carga horária? b) como estas aulas estão sendo desenvolvidas? 3) Em caso de resposta negativa para a questão 1: a) você julga importante inserir a prática como componente curricular nessa disciplina? b) Como você trabalharia essas aulas?

À época em que esse questionário foi aplicado, estava em vigor o Projeto Pedagógico de 2011 que abarcava 29 disciplinas, sendo que dessas, 18 contemplavam a PCC nos moldes da resolução CNE/CP № 1 de 18 de fevereiro de 2002, conforme relatado na seção anterior e as outras 11 não tinham carga horária de PCC.

Professores de 18 disciplinas responderam ao questionário. Dessas, cinco não tinham prática como componente curricular no Projeto Pedagógico. Porém, esses professores disseram desenvolver atividades ligadas a PCC em tais disciplinas. Esse resultado, assim como em Calvo e Freitas (2011), mostra que alguns professores já tinham consciência implícita da importância da prática docente.

Nas 13 disciplinas que tinham PCC, os relatos do CDE, elaborados a partir das respostas desses professores ao questionário supracitado, apontaram que eles desenvolviam a PCC por meio de explorações de softwares utilizados na construção do conhecimento; manuseio de materiais didáticos que podem ser utilizados como suporte às aulas na educação básica; simulações de aulas envolvendo softwares e materiais didáticos; aulas expositivas apresentadas pelos alunos e posteriormente discutidas; leitura e discussão de textos voltados para a prática docente; construção de materiais didáticos para serem utilizados na educação básica; exploração de problemas característicos do cotidiano por meio de observações, por exemplo, observações do meio ambiente, de formas geométricas em construções, de observações no comércio etc.

Além disso, os relatos do CDE apontaram que os professores também desenvolviam a PCC a partir de planejamentos de aulas pelos discentes sob sua 
orientação, com o intuito de articular problemas do cotidiano com o ensino da Matemática; levantamentos e análises de livros didáticos da educação básica sob uma perspectiva crítica; elaborações de planos de aulas e roteiros de apresentação de conteúdos (sob a orientação do professor) nas disciplinas que abordam conteúdos relacionados ao ensino básico.

Professores de 11 disciplinas não responderam ao questionário. Dentre essas, 5 contemplavam e 6 não contemplavam a carga horária de PCC no Projeto Pedagógico de 2011. Esse fato pode ter acontecido porque os professores dessas disciplinas não quiseram expor a maneira em que trabalhavam a PCC na disciplina ou suas ideias sobre ela ou porque não estavam interessados ou não pensavam sobre o assunto ou ainda porque não quiseram se ocupar com 0 preenchimento do questionário. Esse episódio mostra a falta de envolvimento de alguns professores do curso com as discussões sobre a PCC. Entretanto, os dados omitidos se referem a apenas cinco das disciplinas que tinham a PCC, o que representa desconhecimento de menos de 30\% das disciplinas que comtemplam a PCC no curso. Dessa forma, as análises realizadas representam as ideias/opiniões e maneira de trabalhar a PCC na maioria das disciplinas que a contemplavam no Projeto Pedagógico de 2011.

A seguir, são apresentados relatos de experiências vivenciadas em aulas de duas disciplinas em que os docentes buscaram desenvolver a prática como componente curricular por meio de preparação e simulação de aula executada pelos alunos. Esses relatos foram produzidos por dois dos autores deste trabalho a partir das aulas de PCC desenvolvidas antes da concepção desse artigo.

\section{Relato 1}

Refere-se a algumas aulas de Prática como Componente Curricular da disciplina de Laboratório de Ensino de Matemática, na terceira série do curso.

Foi solicitado aos acadêmicos da disciplina que escolhessem um conteúdo matemático, organizassem o planejamento com materiais didáticos adequados e fizessem a apresentação da aula. Foram disponibilizados para eles, livros 
didáticos de Ensino Fundamental e Médio, revistas, sites, materiais disponíveis no laboratório de Ensino de Matemática da Universidade, para que pudessem utilizar como recursos no planejamento das aulas.

Alguns acadêmicos tiveram dúvidas sobre a escolha do conteúdo, queriam escolher o material didático primeiro para, em seguida, fazer a escolha do conteúdo que seria trabalhado. Quando é definido o conteúdo a ser trabalhado, é importante deixar claro os objetivos necessários e, diante disso, organizar o material e a metodologia que poderá ser utilizada para alcançar os objetivos.

A escolha do conteúdo não foi fácil, relacionar o conteúdo a um material didático foi algo que os deixou preocupados, pois quando pensavam em materiais didáticos ou jogos, acreditavam que poderiam ser usados sem a necessidade de um planejamento ou a preocupação com conteúdos.

A aula foi organizada de acordo com as etapas: escolha de conteúdo, definição do material didático, construção do plano de aula e apresentação da mesma, em seguida, a necessidade de reflexão de cada momento da aula. Dessa forma, vivenciaram por meio de aula simulada uma prática que poderia acontecer em uma sala de aula.

Um acadêmico escolheu o conteúdo "adição e subtração com frações" para o sexto ano do Ensino Fundamental e o material didático utilizado foi o "disco de fração", que auxilia na visualização da representação gráfica de uma fração, nas noções de fração e equivalência de frações. Nesse material cada peça representa sua fração correspondente.

As atividades foram realizadas com frações com mesmo denominador. $\mathrm{O}$ acadêmico utilizou como referencial teórico o artigo "As Operações com Números Racionais e seus Significados a partir da Concepção Parte-todo" de Ferreira e Ag Almouloud (2008).

Esse acadêmico trouxe a ideia e o esboço do plano de aula para o professor orientar antes da apresentação da aula. Mesmo tendo bem claro o conteúdo a ser trabalhado, o aluno apresentou dificuldades para organizar o planejamento da aula seguindo as referências sobre plano de aula, que foram 
estudadas nas aulas de Didática da série anterior. O professor justificou a necessidade dos acadêmicos organizarem a aula dessa forma pelo fato de já terem cursado a disciplina de Didática na $2^{-a}$ série e estarem cursando a disciplina de Estágio Supervisionado de Matemática no Ensino Fundamental na terceira série.

Todos os acadêmicos que desenvolveram essa atividade de PCC apresentaram dúvidas, dificuldades e também avanços. Alguns conseguiram compreender o papel do professor no momento de organização da aula, da escolha do conteúdo, de materiais e metodologias e na hora da execução. A partir do momento que conseguiram organizar as ideias e as registraram no plano de aula, a simulação da aula se tornou mais simples. Aqueles que tiveram muitas dificuldades na organização do planejamento, também, tiveram dificuldades na apresentação da aula, pois não conseguiram utilizar o material didático fazendo ligação com o conteúdo planejado, não vinculavam o planejamento com a simulação da aula.

No momento de discussão e reflexão sobre a execução da atividade, os acadêmicos relataram que a atividade proporcionou momentos de dúvidas sobre a parte que eles consideraram como burocrática da aula, a organização do plano de aula. Porém, a intervenção do professor responsável pela disciplina foi muito positiva, possibilitando que compreendessem que a aula inicia desde o momento da escolha do conteúdo, dos materiais e da metodologia, que há um processo na organização de uma aula e que há a necessidade de avaliação de todas essas etapas.

Esse relato mostra que a PCC pode ser usada para que, no desenvolvimento do curso, o aluno pense em como abordar os conteúdos estudados em sala de aula, os materiais e meios para ensiná-los na educação básica. Isto corrobora com Cerri e Dias (2016) no que tange a reflexões das formas de abordagem dos assuntos estudados em uma determinada disciplina. 


\section{Relato 2}

Refere-se a algumas aulas de prática como componente curricular da disciplina de Geometria Euclidiana na primeira série do curso de Matemática.

Foram distribuídos entre os acadêmicos alguns temas/itens relacionados à ementa da disciplina para que elaborassem e ministrassem uma aula. Cada aluno tinha a liberdade de escolher a forma de realização da aula, com a utilização de lousa e giz, projetor de multimídia, materiais didáticos etc. A professora se colocou à disposição para conversar sobre o planejamento e a realização da aula. O principal objetivo era "quebrar o gelo", pois essa era a primeira vez que a maioria deles encararia uma sala de aula com a responsabilidade de lidar com os processos de ensino e de aprendizagem, principalmente por serem alunos da primeira série. A principal regra era que eles levassem a turma a participar da aula. A maioria dos alunos optou por planejar a aula sem intervenção da professora.

No momento da apresentação da aula, alguns alunos ficaram bastante acanhados e diziam que estavam trêmulos. Houve situações em que a professora precisou incentivá-los para que continuassem a aula. Outros ficaram mais à vontade.

Uma acadêmica que ficou responsável por preparar e ministrar uma aula apresentando três demonstrações para o Teorema de Pitágoras fez uma das demonstrações usando um material didático do Laboratório de Ensino de Matemática e depois fez as outras duas utilizando apenas giz e lousa.

Outros dois acadêmicos estavam responsáveis por fazer algumas construções geométricas utilizando régua e compasso, por isso fizeram o uso desses materiais.

Os demais alunos utilizaram apenas giz e lousa para a apresentação da aula. Alguns buscaram envolver os colegas na aula fazendo perguntas para a turma e discutindo o tema. Outros escreveram na lousa por mais de 15 minutos sem nenhum tipo de comunicação verbal com a sala, o que deixou os colegas inquietos. Em alguns desses casos a professora ficou em silêncio, observando o 
desfecho da aula, e em outros buscou incentivar o acadêmico a discutir sobre o que estava escrevendo.

Depois de todos os acadêmicos terem apresentado as aulas, foram realizadas reflexões/discussões gerais (sem citar o nome de um aluno específico) fomentadas com questões do tipo: como vocês acham que os alunos da educação básica se comportariam se o professor permanecesse por vários minutos em silêncio escrevendo na lousa? Vocês acham que o professor deve comunicar com a turma olhando para os alunos? Por quê? Vocês acreditam que conseguiram envolver a turma na aula? Isso é sempre possível? Como vocês fizeram para preparar a aula? Quais foram as fontes pesquisadas e que outras fontes poderiam ser pesquisadas para ajudar no preparo da aula? Quais outros materiais poderiam ter sido utilizados para ministrar as aulas sobre os temas abordados?

Finalmente a professora revelou aos alunos que as discussões/reflexões foram realizadas após todas as apresentações para que os acadêmicos se sentissem mais à vontade para a apresentação, e lembrou que o principal objetivo "quebrar o gelo" foi atingido, pois todos apresentaram suas aulas. Entretanto, a principal regra - levar os demais alunos a participar da aula - foi quebrada na maioria das vezes, mas é um alvo a ser buscado, e que nem sempre depende somente do professor, pois envolve diversos fatores relacionados aos alunos.

Esse relato revela que, no Curso de Matemática da UUC/UEMS, a PCC tem contribuído para a desenvoltura dos alunos, encorajando-os a superar a timidez e o medo de falar em público, possibilitando-os assumir desde o início do curso uma postura profissional, o que está de acordo com os relatos de Fernandes (2004).

O fato dos alunos desenvolverem simulações de aulas desde a primeira série permite que eles compreendam e percebam a realização da PCC no curso, evitando que confusões aconteçam, conforme relatadas por Hoerpes e Fernandes (2012). 


\section{Considerações finais}

As atividades desenvolvidas pelos professores do Curso de Matemática da UUC/UEMS, em relação à PCC, mostram a maneira que eles têm interpretado e buscado atender às recomendações da resolução CNE/CP № 1 de 18 de fevereiro de 2002. A prática como componente curricular tem sido implementada, paulatinamente, ao longo da existência do curso, conforme descrito nesse trabalho. Porém, conforme Manrinque e Perentelli (2008), ainda é necessário muito esforço e trabalho para que a PCC aconteça plenamente.

O Curso de Matemática da UUC/UEMS tem interpretado a PCC como uma ação que deve possibilitar ao aluno vivenciar experiências úteis para 0 desenvolvimento da docência no âmbito da educação básica. Nessa perspectiva, a PCC tem estimulado a atuação dos alunos em situações que enfrentarão como futuros professores, por exemplo, as descritas nos relatos 1 e 2.

Além disso, os relatos 1 e 2 mostram que para desenvolver a PCC, 0 professor deixa de ser o ator principal e passa a conduzir os alunos para que preparem e desenvolvam as aulas. Essa conduta não condiz com o modelo tradicional de aula em que os alunos são expectadores e o professor atua como um palestrante. Dessa forma, acredita-se que as reflexões geradas ao desenvolver a PCC nas aulas têm possibilitado a alguns docentes refletirem/repensarem e reconstruírem suas próprias práticas pedagógicas, rompendo com o modelo de formação tradicional, que muitos deles, vivenciaram ao longo de décadas na condição de alunos. Segundo Coura e Passos (2017), há certa dificuldade dos formadores de, em seu fazer docente, romper com modelos nos quais eles próprios foram formados, e, de acordo com Lamblém e Bittar (2018), para que se despoje de práticas antigas e conceitos arraigados necessitase de esforço, convicção e dedicação, mas, sobretudo necessita-se de uma mudança de paradigmas.

O estudo da resolução CNE/CP № 1 de 18 de fevereiro de 2002, leituras de materiais relacionados a essa resolução e discussões promovidas pelo corpo docente do Curso de Matemática da UUC/UEMS geraram, em alguns docentes 
do curso, a percepção da importância da PCC na formação do futuro professor de Matemática, impulsionando-os para a mudança de paradigmas.

Assim, parece razoável associar a prática como componente curricular a uma postura a ser mantida no dia a dia do professor, por isso, para desenvolvê-la, são necessários planejamento e reflexões das próprias atitudes no exercício da docência. Afinal, como um professor lida com os dilemas vivenciados em sala de aula e, pensa sua própria prática pedagógica? Que coerência há entre o que diz e o que pratica? Nesse cenário, a prática como componente curricular continuará sendo refletida e discutida pelos professores do Curso de Matemática da UUC/UEMS, tendo como objetivos, buscar atividades que aperfeiçoem cada vez mais a formação docente, ser coerente com o dito e o realizado e superar os desafios dos processos de ensino e de aprendizagem que vão surgindo no decorrer da caminhada docente, dia após dia.

\section{Referências}

BARBOSA, Alessandro Tomaz; CASSIANI, Suzani. Sentidos da prática como componente curricular nos documentos do conselho nacional de educação. Revista da SBEnBio, v. 7, p. 195-204, 2014.

BORINI, Rafael Borini Martins Costa. Prática como Componente Curricular no Curso de Licenciatura de Matemática: um estudo documental à luz do conceito de prática. Anais do XX - EBRAPEM - Encontro Brasileiro dos Estudantes de Pós-Graduação em Educação Matemática, Curitiba, 12 a 14 de Novembro de 2016. Disponível em: <http://www.ebrapem2016.ufpr.br/wp-content/uploads/2016/04/gd7_rafael_borini.pdf>. Acesso em: 20 fev. 2018.

BRANDALISE, Mary Angela Teixeira; TROBIA, José. A prática como componente curricular na licenciatura em Matemática: múltiplos contextos, sujeitos e saberes. Educação Matemática e Pesquisa, v. 13, n. 2, p. 337-357, 2011.

BRASIL 2002a - Diretrizes Curriculares Nacionais para a Formação de Professores da Educação Básica, Resolução CNE/CP № 1, Brasília, 18 de Fevereiro de 2002.

BRASIL 2002b - Diretrizes Curriculares Nacionais para a Formação de Professores da Educação Básica, Resolução CNE/CP № 2, Brasília, 19 de Fevereiro de 2002.

BRASIL 2015 - Diretrizes Curriculares Nacionais para a formação inicial em nível superior (cursos de licenciatura, cursos de formação pedagógica para graduados e cursos de 
segunda licenciatura) e para a formação continuada, Resolução CNE/CP № 2, Brasília $1^{\circ}$ de julho de 2015.

CALVO, Luciana Cabrini Simões; FREITAS, Maria Adelaide de Freitas. Prática como componente curricular e sua implementação em sala de aula na visão de formadores de um curso de Letras. Acta Scientiarum. Language and Culture, v. 33, n. 2, p. 315-327, 2011.

CERRI, Cristina; DIAS, David Pires. A Prática como componente curricular em uma disciplina de análise real. Educação Matemática em Revista, v. 49B, p. 26 - 34, 2016. COURA, Flávia Cristina Figueiredo; PASSOS, Cármen Lúcia Brancaglion. Estado do conhecimento sobre o formador de professores de Matemática no Brasil. Zetetiké, v.25, n1, p.7-26, 2017.

FERNANDES, Cleoni Maria Barboza. A prática como componente curricular: uma possibilidade de inovação ou uma re-semantização retórica na organização curricular dos cursos de formação de professores? - Anais do V ANPEDSUL - Seminário de Pesquisa em Educação da Região Sul, Curitiba, 27 a 30 de abril, 2004. Disponível em: <http://www.portalanpedsul.com.br/admin/uploads/2004/Mesa_Redonda/Mesa_Redonda/ 07_15_02_A_PRATICA_COMO_COMPONENTE_CURRICULAR_UMA_POSSIBILIDAD E_DE_IN.pdf $>$. Acesso em: 10 jan. 2018.

FERREIRA DA SILVA, Maria José; AG ALMOULOUD, Saddo. As Operações com Números Racionais e seus Significados a partir da Concepção Parte-todo. Boletim de Educação Matemática, v. 38, p. 55 -78, 2008.

FIGUEIREDO, Sonner Arfux de; COSTA, Nielce Meneguelo Lobo da. A Prática como componente curricular na Licenciatura em Matemática da Universidade Estadual de Mato Grosso do Sul. Anais do II COLBEDUCA - Colóquio Luso-Brasileiro de Educação, Joinvile, p. 137 - 150, 5 a 6 de setembro de 2016. Disponível em: $<$ www.revistas.udesc.br/index.php/colbeduca/article/download/8148/6086>. Acesso em: 07 fev. 2018.

HOERPES, Idorlene da Silva; FERNANDES, Sônia Regina de Souza. A prática como componente curricular na representação dos estudantes de licenciatura em Matemática: entre o dito e o feito. Anais da IX ANPED SUL - Seminário de Pesquisa em Educação da Região Sul - Anais... Caxias do Sul, 29 de julho a $1^{\circ}$ de agosto, 2012. Disponível em: $<$ http://www.ucs.br/etc/conferencias/index.php/anpedsul/9anpedsul/paper/viewFile/1565/9 55>. Acesso em: 25 maio 2018.

LAMBLÉM, Regina Litz; BITTAR, Marilena. Reflexões sobre a teoria das situações didáticas por duas pesquisadoras em diferentes estágios da vida acadêmica. Educação Matemática e Pesquisa, v.20, n.2, p. 202-221, 2018.

MANRINQUE, Ana Lúcia; PERENTELLI, Leia Fernandes. Um estudo sobre a prática como componente curricular Em cursos de licenciatura em Matemática. In: VII Congresso Nacional de Educação - VIII EDUCERE - Curitiba, 06 a 08 de outubro, 2008. Disponível em: 
$<$ http://www.pucpr.br/eventos/educere/educere2008/anais/pdf/737 526.pdf > . Acesso em: 13 fev. 2018.

NOGUEIRA, Kely Fabricia Pereira; PEREIRA, Patrícia Sândalo. A prática como componente curricular via projetos: uma alternativa para a formação de professores.

Anais do XVI ENDIPE - Encontro Nacional de Didática e Práticas de Ensino, Campinas, 23 a 26 de julho, 2012a. Disponível em:

$<$ http://www.infoteca.inf.br/endipe/smarty/templates/arquivos template/upload arquivos/a cervo/docs/2832b.pdf>. Acesso em: 28 jan. 2018.

NOGUEIRA, Kely Fabricia Pereira; PEREIRA, Patrícia Sândalo. Prática como componente curricular: uma proposta para a licenciatura em Matemática. Anais do V Seminário Internacional de Pesquisa em Educação Matemática, Petrópolis, 28 a 31 de outubro, 2012b. Disponível em: $<$ http://www.sbembrasil.org.br/files/v sipem/PDFs/GT07/CC55365639634 B.pdf>. Acesso em: 17 fev. 2018.

ROCHA, Hallayne Nadal Barboza. A Prática como Componente Curricular na Formação Inicial do Professor de Matemática: uma leitura da Resolução CNE/CP 01/2002. Anais do XIX - EBRAPEM - Encontro Brasileiro dos Estudantes de Pós-Graduação em Educação Matemática, Juiz de Fora/MG - 30 de outubro a 2 de novembro de 2015. Disponível em: <http://www.ufjf.br/ebrapem2015/files/2015/10/dg7 Hallayne Rocha.pdf>. Acesso em: 13 abril. 2018.

SARRO, Luciane Cristina; SCHNETZLER, Roseli Pacheco. A Prática como Componente Curricular da Licenciatura em Matemática: Sugestões de Professores da Educação Básica. Revista Eletrônica de Educação Matemática, v. 10, n. 2, p. 185 - 196, 2015.

UEMS 2000 - Projeto pedagógico do Curso de Matemática da Unidade Universitária de Cassilândia, Resolução PROAC-UEMS n ${ }^{\mathbf{5}}$, Dourados 12 de dezembro de 1997.

UEMS 2005 - Projeto pedagógico do Curso de Matemática da Unidade Universitária de Cassilândia, Resolução CEPE-UEMS n 514, Dourados, 28 de abril de 2005.

UEMS 2011 - Projeto pedagógico do Curso de Matemática da Unidade Universitária de Cassilândia, Resolução CEPE- UEMS n ${ }^{\circ}$ 118, Dourados, 21 de novembro de 2005.

ZABEL, Marília; MALHEIROS, Ana Paula dos Santos. Entendendo a Prática de Ensino nos Cursos de Formação Inicial de Professores que Ensinam Matemática a partir dos Documentos Legais. Educação Matemática em Revista, v. 49A, p. 8-16, 2016. 